\title{
Mulheres negras nos jornais: exclusão, gênero e etnia*
}

"Nós, negros sempre teremos situações de racismo para enfrentar. Isso não acaba com a fama, com o dinheiro, com o poder, nem com nada". Glória Maria - A cor do Sucesso

\section{RESUMO}

As mulheres negras no Brasil não são uma minoria. Porém, ao compararmos suas condições com as do restante da população, percebemos que as mulheres negras e pardas compõem a faixa mais discriminada do país, sofrendo com as maiores dificuldades econômicas e sociais. Essa pesquisa é um desdobramento de outro estudo já realizado em 2005 e 2006 e intitulado "Democracia Mediática e Visibilidade: presença de negros nas fotografias dos jornais catarinenses". Desta vez, retornamos à investigação, adicionando ao fator étnico a questão de gênero.

\section{PALAVRAS-CHAVE}

mulheres negras

discriminação

imprensa catarinense

\section{ABSTRACT}

Black women in Brazil are not a minority. However, by comparing their conditions to the rest of the population, we realize that black women put together the most discriminated portion of the country, standing the highest economical and social difficulties. This research is the extending of another study, done in 2005 and 2006 and entitled "Mediatic Democracy and Visibility: the presence of black people in photography at newspapers from Santa Catarina". This time, we recover the topic, adding a matter of gender into the ethnical factor.

\section{KEY WORDS}

black women

discrimination

Santa Catarina's press

\section{Rogério Christofoletti}

Professor da Univali/SC/BR

rogerio.christofoletti@uol.com.br

\section{Roberta Cunha Watzko}

Graduanda em Comunicação Social/jornalismo da Univali/SC/BR. beta_w@hotmail.com
0 Brasil é a nação com maior número de negros fora do continente africano. Segundo o Censo de 2000, existem mais de 75 milhões de negros e pardos no país. Apesar do grande mosaico étnico existente, o mito da democracia racial está muito longe de ser uma realidade vivenciada pelos brasileiros. O Brasil conta com $45,6 \%$ da sua população sendo negra, entretanto esse grupo ainda é tratado como se fosse minoria. A desigualdade social existente revela um abismo na comparação entre negros e brancos. Conforme a Pesquisa Nacional por Amostra de Domicílio (PNAD) de 2006, entre os 10\% mais pobres do país $73,2 \%$ são negros e pardos. Já na fatia do $1 \%$ mais rico da população apenas $12,4 \%$ são negros. Isto é, os não-brancos são excluídos até mesmo na porção mais privilegiada economicamente.

Levantamento realizado em meados dos anos 90 pelo Datafolha descobriu que apesar de $89 \%$ das pessoas afirmarem que existe preconceito de cor no Brasil, apenas $10 \%$ admitiam possuir esse preconceito (Turra e Venturi, 1995, p. 11). Porém, de forma indireta, $87 \%$ das pessoas revelaram ser preconceituosas ao pronunciar ou concordar com frases de conteúdo racista. O fato é que as pessoas tentam minimizar o preconceito, talvez como forma de incorporar o que Sérgio Buarque chama de "homem cordial", uma atitude típica do brasileiro. "Indagado se é racista, o brasileiro, cordialmente, nega. [...] Essa cordialidade equivale a um disfarce que permitirá a cada qual preservar inatas suas sensibilidades e emoções". (Buarque, 1995, p. 12)

O fato de o racismo ser tão bem escondido pelas pessoas não impede que ele exista e que afete as populações negras e pardas. Há várias estatísticas que mostram que esses contingentes estão bem atrás dos brancos em quesitos sociais e econômicos. Glória Maria, jornalista e uma das personalidades negras mais famosas e de sucesso do país, conta que o racismo que o brasileiro está acostumado a praticar é um "racismo covarde", e que ela usou isso a seu favor.

Tenho uma coisa muito legal: não sou 'mulatinha', sou negra mesmo. A cor, na verdade, sempre me abriu portas. Porque, até para ser racista, você tem de ter coragem, e as pessoas estão acostumadas a exercitar um racismo covarde. Você pode manifestar-se sutilmente, falar pelas costas, mas dificilmente tem coragem de ser racista na cara. Talvez eu tenha usado o racismo para o outro lado. Sabendo que mesmo as pessoas racistas tinham uma preocupação forte em não demonstrar o racismo, usei a minha cor para abrir portas que outras pessoas não abriam. Eu chegava, entrava e todo mundo ficava meio preocupado em dizer 'não entre' e que isso fosse interpretado como um gesto racista. Eu usava 
a falta de caráter e de coragem das pessoas para ter acesso a coisas que os outros não conseguiam. [...] a hesitação deles era a minha deixa para entrar. (Macedo e Faustino, 2000, p. 156)

Segundo o Datafolha, para $48 \%$ dos negros entrevistados, a frase "Negro bom é negro de alma branca" tem seu fundo de verdade. Isso mostra o quanto o racismo está enraizado na cultura brasileira e como isso influencia e afeta a própria auto-estima dos afro-descendentes. (Turra e Venturi, 1995, p. 26)

\section{Todos esses dados revelam que 0 tratamento dedicado às mulheres negras e pardas é diferente do ofertado às brancas.}

Anos atrás, aconteceram algumas situações em que o racismo não apareceu de forma tão velada assim no Brasil. Na década de 80, surgiram na Bahia alguns anúncios carregados de intolerância e de racismo. Eles foram produzidos pelo Centro de Pesquisa e Assistência em Reprodução Humana para divulgar um programa de planejamento familiar gratuito. Um deles tinha o título "defeito de fabricação" e abaixo trazia uma imagem de um garoto negro, com correntes no pescoço, canivete na mão e tarja nos olhos com o seguinte texto: "Tem filho que nasce para ser artista. Tem filho que nasce para ser advogado e vai ser embaixador. Infelizmente, tem filho que já nasce marginal". Outro anúncio mostrava a foto de uma mulher negra grávida, coberta com um lençol branco e a legenda "também se chora de barriga cheia" (Sodré, 1999, p. 234). O fato chocou a imprensa brasileira, parecia que o preconceito de cor estava deixando de ser dissimulado para se tornar explícito.

Na mesma década, o Grupo de Assessoria e Participação do Governo do Estado de São Paulo (GAP) propôs a esterilização massiva de mulheres negras, com o argumento de que projeções indicavam o crescimento da população de cor e que isto provavelmente resultaria na ocupação de poder por afro-descendentes. O documento acabou se tornando público devido a denúncias e, assim, a ação pôde ser contestada.

A sociedade brasileira jamais conseguiu impor uma endogamia racial, fato comprovado pela realidade da miscigenação. Embora o acesso às posições de poder tenha-se tornado inviável para negros, firmou-se progressivamente a negociação com mulatos, porque a segregação pura e simples, baseada na supremacia branca, não tinha (apesar do racismo científico do final do século passado) nenhuma justificativa ética nem legitimidade social. [...] Mes- mo parecendo acreditar na superioridade branca, as elites nacionais elaboraram um discurso de transigência, o da mestiçagem biológica e cultural, que gerou simultaneamente as ideologias do embranquecimentoe da democracia racial. (Sodré1999, p. 103)

\section{Condições da mulher negra no Brasil}

De acordo com o Censo do IBGE, em 2000, havia no país aproximadamente 37,4 milhões de mulheres negras, contingente populacional que já é maior no final desta década. Segundo a antropóloga e fundadora do Geledés Instituto da Mulher Negra -, Sueli Carneiro, os grupos de afro-descendentes femininos possuem demandas específicas e não devem ser tratadas unicamente pela ótica da questão do gênero. É importante levar em conta as suas especificidades, além de serem mulheres, elas são negras (Carneiro, 2003). Em face dessa dupla desvalorização, as mulheres negras são a fatia mais marginalizada da sociedade. Mas, segundo Carneiro, isso não é um simples acaso, mas sim provém de uma cotidiana discriminação.

Dados da Pesquisa Nacional por Amostra de Domicílio de 2003 revelam que as mulheres negras recebem os salários mais baixos do país (IBGE, 2003). A renda mensal dessas mulheres é de apenas 30\% se comparada a dos homens brancos e de $50 \%$ se comparada a das mulheres brancas. Essas negras ainda são a parcela da população com a maior taxa de desemprego do Brasil $52 \%$ do total do contingente estão sem emprego.

A falta de atendimento na área da saúde também é mais aguda para as negras. Em 2004, a PNAD revelou um dado preocupante: $46,3 \%$ dessas mulheres com mais de 25 anos nunca haviam realizado um exame clínico de mamas, já entre as brancas esse mesmo índice era de $28,7 \%$. A morte materna também é uma realidade muito mais presente na vida de negras e pardas. Segundo o Ministério da Saúde, a taxa de morte é quase seis vezes maior nelas do que nas brancas (IBGE, 2004).

Pesquisa realizada pela Fundação Fiocruz em parceria com a Prefeitura do Rio de Janeiro e divulgada pela Folha de S. Paulo (Petry, 2002) revelou diferenças também no tratamento de gestantes negras e não negras. Enquanto as brancas não recebiam anestesia em apenas $5,1 \%$ dos casos de parto, as negras não recebiam em $11,1 \%$ das ocorrências. Até no recebimento de informações a respeito do pré-natal as afro-descendentes saíam perdendo. A porcentagem de negras não informadas da importância do exame ainda era maior do que a das brancas. E enquanto 5,1\% das negras não realizaram o exame, apenas 2,5\% de brancas não o fizeram. A desigualdade social pode ser vista até na hora dessas mulheres receberem um acompanhante antes ou depois do parto. Enquanto 46,3\% das brancas puderam ter ao lado a presença de alguém da família, apenas $27 \%$ das negras tiveram essa permissão.

Todos esses dados revelam que o tratamento dedicado às mulheres negras e pardas é diferente do ofertado 
às brancas. Isso indica a importância de ações educativas do governo, tanto com as próprias mulheres, como com os profissionais da área da saúde. Indica ainda a necessidade de ações de promoção de igualdade de tratamento.

\section{Afro-descendentes na "Europa brasileira"}

O sul do Brasil é conhecido como a região mais branca do país. Fatores como os movimentos imigratórios e a distribuição da população redefiniram o perfil étnico da região. A imagem projetada do estado de Santa Catarina é, genericamente, de um povo descendente de europeus, de olhos azuis e de cabelos loiros, estereótipo que acaba ocultando os $12,5 \%$ de negros presentes na população local.

\section{Assim, indivíduos do sexo feminino, com cabelos crespos, lábios grossos, nariz aberto e cor da pele escura foram considerados negros, $\mathrm{e}$ constaram das estatísticas referentes a esta etnia.}

Santa Catarina, segundo o Censo de 2000, é o segundo estado com melhor Índice de Desenvolvimento Humano do país. Entretanto, essa imagem só parece refletir e estar atrelada à população branca. A parcela negra continua sofrendo com os mesmos problemas do restante do país. Enquanto a média da taxa de analfabetismo da população branca no estado é de 5,1\% a de afro-descendentes é de $12 \%$.

Conforme dados do IBGE, a porcentagem de mulheres negras no estado em 2000 era de 4,5\%. Em 2006, a PNAD divulgou um aumento de $2,9 \%$ na população não-branca do estado, incluindo sujeitos dos dois sexos. Esse dado nos leva a concluir que, atualmente, a porcentagem de negras e pardas em Santa Catarina é maior do que a divulgada no último censo, certamente superior a $5 \%$.

Estudo do Instituto de Pesquisa Econômica Aplicada (Ipea), de 2005, revela que o Brasil é o segundo pior país no mundo em distribuição de renda, e quem mais padece com isso é a população negra. Um terço dos brasileiros é considerado pobre - quase 54 milhões de pessoas e $44,1 \%$ são negros, contra $20,5 \%$ de brancos. "As maiores desigualdades entre negros e brancos estão nas regiões Sul e Sudeste, com destaque para Santa Catarina, que apresenta uma proporção duas vezes e meia maior de negros pobres que de brancos pobres", informa Már- cia Costa na edição de 2 de junho de 2005 do jornal $A$ Notícia. Os catarinenses negros pobres são $26,4 \%$ enquanto que os brancos pobres estão na casa dos 10,3\%, menos da metade!

Em Santa Catarina, a desigualdade racial também é evidente. Embora 12,5\% da população catarinense seja negra, os afro-descendentes não aparecem na mesma proporção na imprensa do estado. Christofoletti e Basso (2007) fizeram uma pesquisa da presença de negros e mestiços nas fotografias dos três principais jornais de Santa Catarina por quase seis meses, e detectaram três aspectos que dificultam ainda mais a visibilidade desses contingentes:

Negros e afro-descendentes foram retratados em 4995 fotos de um total de 53634, de agosto de 2005 a maio de 2006 , o que significa $9,31 \%$ de presença. O índice é $11 \%$ menor que a representatividade desses personagens na população catarinense;

Em apenas 3,04\% das fotos em que aparecem negros e pardos estão nas editorias consideradas nobres (Economia e Política);

Em contraste, figuram maciçamente nas editorias de Esportes e Cultura, alcançando 69,5\% das ocorrências, o que reforça os estereótipos de que negros "se dão melhor" com música e futebol do que com assuntos mais sérios, como política e economia.

A pesquisa intitulada confirmou duas hipóteses e negou uma terceira. As idéias de que os negros e pardos apareceriam pouco nos jornais (menos ainda que sua própria representatividade na população) e que estariam relegados a algumas editorias-guetos foram observadas no período analisado. Já a intuição de que esses personagens seriam assíduos nas páginas do noticiário policial caiu por terra, já que negros e afro-descendentes apareceram em apenas 90 fotografias dessa editoria $(1,8 \%$ das ocorrências).

Com esses dados, Christofoletti e Basso (2007) puderam esboçar um quadro genérico da visibilidade dos negros nas fotos dos jornais locais. Entretanto, mesmo dentro desse universo étnico, há nuances que podem ser mais bem compreendidas. Será que as mulheres têm uma visibilidade maior do que os homens negros? Em que medida isso se dá? E em que condições elas se apresentam nas vitrines jornalísticas? Um desdobramento da pesquisa dos autores é o que se propõe aqui, concentrando as atenções sobre o cruzamento dessas duas condições marginalizadas: ser mulher e negra.

Santos (2006) cita o estudo de Joel Zito Araújo (2000) acerca da presença dos negros nas telenovelas brasileiras entre 1963 e 1997. As conclusões do autor apontam para o fato de que os papéis interpretados pelos negros difundem uma imagem negativa, o que pode levar o público a se identificar apenas com os personagens vivi- 
dos por atores brancos, "criando um padrão de esquizofrenia para os negros".

Santos ressalta a pouca participação dos negros nas telenovelas e a freqüência de "relações de amor entre mulheres negras e homens brancos" (2006, p. 52).

Nas novelas, as mulheres negras encaram o vínculo com o homem branco como uma forma de projeção social. Estar unidas a ele representaria que, de algum modo, superaram a barreira da discriminação e adicionaram algum elemento de positividade que pudesse contrabalançar a carga de estereótipos que as envolveriam. O homem branco seria o ícone do fortuito que a livraria de sua condição de pária (Santos, 2006, p. 54).

Segundo a autora, as telenovelas nacionais, na medida em que trabalham nesta perspectiva simbólica e atingem grandes públicos, tornam-se um "veículo ímpar na divulgação e perpetuação de estereótipos, ao mesmo tempo em que veiculam imagens de harmonia", dissol- vendo o conflito étnico e reeditando o mito da democracia racial.

A mídia impressa - como os jornais analisados por Christofoletti e Basso (2007) - também pode servir a isso, daí a necessidade de voltar a se debruçar sobre eles, identificando a presença de personagens negros nas fotos e percebendo nessas ocorrências a figuração da mulher negra.

\section{Aspectos metodológicos}

A pesquisa sobre a presença de mulheres negras e pardas nas fotografias dos principais jornais catarinenses conjugou basicamente duas técnicas: revisão bibliográfica sobre o tema e monitoramento dos jornais, com a contabilização e classificação das fotografias publicadas.

Com a revisão bibliográfica efetuada, passou-se a monitorar por cinco meses os três principais jornais do estado - A Notícia, Jornal de Santa Catarina e Diário Catarinense - que, juntos, cobrem todo o território local e representam as maiores tiragens diárias. O período compre-

Tabela 1 Visibilidade das negras e dos negros por período e por jornal.

\begin{tabular}{|c|c|c|c|c|c|}
\hline Jornal e período & Total fotos & Com pessoas & Com Negros & Com Negras & $\%$ negras/fotos com pessoas \\
\hline$A N-10 / 2007$ & 1795 & 1485 & 180 & 21 & $1,41 \%$ \\
\hline$A N-11 / 2007$ & 2245 & 1943 & 206 & 41 & $2,11 \%$ \\
\hline AN - 12/2007 & 2126 & 1812 & 165 & 46 & $2,54 \%$ \\
\hline AN - 01/2008 & 2250 & 1933 & 229 & 47 & $2,43 \%$ \\
\hline AN- 02/2008 & 1932 & 1709 & 219 & 34 & $2,00 \%$ \\
\hline NA - TOTAL & 10348 & 8882 & 999 & 189 & $2,13 \%$ \\
\hline DC - 10/2007 & 2413 & 2042 & 230 & 45 & $2,20 \%$ \\
\hline DC - 11/2007 & 3011 & 2726 & 276 & 51 & $1,87 \%$ \\
\hline DC - 12/2007 & 2753 & 2331 & 235 & 76 & $3,26 \%$ \\
\hline DC - 01/2008 & 3214 & 2756 & 281 & 85 & $3,08 \%$ \\
\hline DC - 02/2008 & 2955 & 2530 & 251 & 75 & $2,97 \%$ \\
\hline DC - TOTAL & 14346 & 12385 & 1273 & 332 & $2,68 \%$ \\
\hline JSC - 10/2007 & 1601 & 1186 & 86 & 21 & $1,77 \%$ \\
\hline JSC - 11/2007 & 2050 & 1650 & 126 & 35 & $2,12 \%$ \\
\hline JSC - 01/2008 & 2139 & 1648 & 147 & 40 & $2,42 \%$ \\
\hline JSC - 02/2008 & 1846 & 1439 & 137 & 27 & $1,87 \%$ \\
\hline JSC - 03/2008 & 1942 & 1543 & 95 & 32 & $2,07 \%$ \\
\hline JSC - TOTAL & 9578 & 7466 & 591 & 155 & $2,07 \%$ \\
\hline TOTAL & 34272 & 28733 & 2863 & 676 & $2,35 \%$ \\
\hline
\end{tabular}

Fonte: A Notícia, Diário Catarinense e Jornal de Santa Catarina, 10/2007 a 02/2008. 
Tabela 2

Visibilidade das negras nas editorias dos jornais

\begin{tabular}{|llc|}
\hline & & \\
\hline Variedades / Lazer & 221 & $32,6 \%$ \\
Geral & 126 & $18,6 \%$ \\
Politica & 35 & $5,2 \%$ \\
Economia & 34 & $5,0 \%$ \\
Polícia/Segurança & 13 & $1,9 \%$ \\
Mundo & 25 & $3,7 \%$ \\
Capa & 35 & $5,2 \%$ \\
Contracapa & 21 & $3,1 \%$ \\
Esportes & 62 & $9,2 \%$ \\
Destaque/Especial & 27 & $4 \%$ \\
Outras Seções & 77 & $11,5 \%$ \\
Total & 676 & -- \\
\hline
\end{tabular}

Fonte: A Notícia, Diário Catarinense e Jornal de Santa Catarina, 10/2007 a 02/2008.

endido para análise foi de outubro de 2007 a fevereiro de 2008, exceto pelo Jornal de Santa Catarina - que, por problemas operacionais, não foi analisado em dezembro, mas em contrapartida teve o mês de março incluído, de forma a manter a mesma quantidade de dias do período já previsto.

Nesta etapa, os procedimentos metodológicos se resumiram à observação cuidadosa de todas as edições dos jornais, contagem das fotografias jornalísticas publicadas, identificação e catalogação daquelas em que figuravam mulheres negras e pardas. Para tanto, foram adotados critérios bem definidos do que se considerou indivíduo negro. Detivemo-nos nas chamadas características fenotípicas, isto é, na aparência dos sujeitos, e não em quesitos genéticos. Assim, indivíduos do sexo feminino, com cabelos crespos, lábios grossos, nariz aberto e cor da pele escura foram considerados negros, e constaram das estatísticas referentes a esta etnia. Apesar de existir certo grau de subjetividade nessa análise, é possível perceber com facilidade quando um sujeito é do tipo caucasiano ou não. Negras, mestiças e pardas foram tratadas, sem distinção, como afro-descendentes na pesquisa.

Após a contagem e a catalogação das fotos por editoria, foi necessário organizar esses dados em tabelas para transformá-los em números e estatísticas. Foram feitas comparações com a fatia da população da etnia no estado, bem como a observância de aspectos como a localização das fotos nas editorias e as possíveis conseqüências dessa disposição. A identificação das imagens em que aparecem mulheres negras e pardas, e os detalhes de sua publicação permitiu traçar considerações acerca da presença das negras nos jornais locais.

\section{Negras nos jornais catarinenses}

O mapeamento da presença das mulheres negras nas fotografias dos jornais catarinenses mostrou uma quase invisibilidade delas na imprensa do estado. Durante os cinco meses analisados, foram publicadas 34272 fotografias jornalísticas, das quais, 28733 continham pessoas. Entretanto, apenas 676 contavam com mulheres afro-descendentes. Nos três jornais escolhidos - $A$ Notícia, Diário Catarinense e Jornal de Santa Catarina -, percebeu-se a presença dessas negras em apenas 2,35\% das fotografias com pessoas.

Essa visibilidade midiática é bem menor do que a presença física desse contingente populacional no estado. Conforme o IBGE de 2000, 4,5\% da população de Santa Catarina é de mulheres negras, entretanto o periódico que ficou menos distante dessa quantidade foi o Diário Catarinense com a participação de 2,68\% de negras e pardas nas fotografias. Em seguida, ficou A Notícia (2,13\%) e, por fim, o Jornal de Santa Catarina com 2,7\%.

É evidente que não se espera que os meios de comunicação sigam aspectos geográficos e estatísticos para realizar seu trabalho. No entanto, espera-se que a mídia possa - de alguma forma - ser pluralista, democrática e diversa; que contemple a diferença em faixas como o gênero, a etnia, a condição social, as manifestações culturais, etc. $\mathrm{E}$ a inexpressiva presença das mulheres afro-descendentes na mídia impressa catarinense mostra uma tendência contrária a isso. Exibe um viés de embranquecimento das camadas populacionais, reforçando o estereótipo do descendente europeu, do "macho, adulto, branco, sempre no comando", como já cantou Caetano Veloso em O estrangeiro.

Em termos de ocorrência de fotos por mês e por jornal, observou-se que as mulheres negras e pardas mais apareceram em dezembro, no Diário Catarinense (taxa de $3,26 \%$ ); no outro extremo, elas figuraram menos em outubro, em A Notícia (1,41\%). O detalhamento desta distribuição pode ser visto na Tabela 1 .

Fazendo uma comparação entre a quantidade de homens negros e pardos e mulheres das mesmas etnias nas fotografias dos jornais, a diferença das ocorrências é muito expressiva. No Diário Catarinense, por exemplo, aparecem 1273 fotos com os homens contra apenas 332 fotos com as mulheres no mesmo período de análise. Isto é, há uma proporção de uma mulher para quatro homens retratados. Essa diferença se estendeu também ao Jornal de Santa Catarina que estampou 591 fotografias de homens afro-descendentes contra 155 de mulheres. Em A Notícia, a invisibilidade delas foi ainda maior, já que foram apenas 189 fotos contra 999 das com homens, uma relação de 1 para cada 5 .

Nos três jornais somados, homens negros apareceram em $9,9 \%$ das fotografias e as mulheres em apenas 2,35\%. Esses números nos mostram que até na imprensa as 
negras continuam sendo a classe mais discriminada, mais invisível.

$\mathrm{Na}$ análise das ocorrências divididas por editoria, todos os jornais apresentaram predominância da presença de negras e pardas na seção Variedades/Cultura/Lazer. No jornal A Notícia, 47,1\% das fotos com a presença delas estava nesse setor. Na soma dos jornais, $32,6 \%$ das imagens com mulheres afro-descendentes estava nessa seção, isto é, praticamente um terço. A segunda editoria com maior número de ocorrências foi a Geral, com $18,6 \%$, seguida pela de Esportes com 9,2\%. Os registros veiculados nas páginas de maior destaque do jornal, Capa e Contracapa, somaram 8,3\%. Na seção de Política, encontramos 5,2\% de fotos com negras e pardas.

\section{Tabela 3}

Mulheres negras e pardas nos jornais, conforme sua posição e função social

\begin{tabular}{|c|c|c|c|}
\hline AC & EA & PE & OP \\
\hline $32,4 \%$ & $8,4 \%$ & $3,4 \%$ & $55,8 \%$ \\
\hline
\end{tabular}

Fonte: A Notícia, Diário Catarinense e Jornal de Santa Catarina, 10/2007 a 02/2008.

A Tabela 2 detalha essa divisão nas páginas dos jornais.

A forte presença de mulheres negras e pardas nas seções de Cultura/Variedades/Lazer bate de frente com a pequena figuração dessas nas editorias de Política e Economia, por exemplo, setores de maior influência no noticiário. Essa constatação ajuda a reforçar estereótipos como os de que as afro-descendentes são melhores em atividades que não exijam tanto esforço intelectual ou instrução formal, e que dependam apenas de talento e outros atributos. Isto é, fica subentendido que elas pouco participam das decisões econômicas e políticas, já que são praticamente invisíveis nessas páginas, e que só se destaquem como atrizes, cantoras, artistas.

Tal deslocamento na mídia reflete, genericamente, um entendimento popular de que a sociedade loteia postos de comando e influência. Sob essa ótica que é reforçada pelas páginas dos jornais, mulheres pardas e negras ficariam alijadas dos processos de decisão e condução dos processos sociais mais relevantes, cabendo a elas ações secundárias e menos determinantes.

Para observar com mais atenção essa figuração de negras e pardas nos jornais, catalogamos as fotografias encontradas em quatro categorias funcionais: Artistas e Celebridades (AC), Esportistas e Atletas (EA), Políticas e Agentes da Economia (PE) e Outras Pessoas (OP). Tabulados dessa forma, os resultados compõem a Tabela 3:

A maior parte das fotos encontradas (55,8\%) foi de mulheres em geral (OP). No entanto, nem todas as fotos encontradas eram de mulheres negras em primeiro plano. Grande parte dessas imagens continha personagens apenas como fundo, sem ser o foco do retrato realizado.

\section{Em todos os jornais analisados, a quantidade de fotografias com mulheres negras e pardas não chegou nem perto de alcançar 0 percentual delas na população do estado.}

A segunda categoria que mais contemplou as mulheres afro-descendentes foi a de Artistas e Celebridades (AC), com 32,3\%. As fotos mais comuns eram de atrizes de televisão como Juliana Paes (16 ocorrências), Sheron Menezes (9), Ildi Silva (9), Camila Pitanga (8), Glória Maria (7), entre outras. Entre as cinco que mais apareceram nos jornais, quatro carregavam o estereótipo de símbolo sexual, reforçando uma imagem antiga. O mito da sexualidade exacerbada acompanha as negras desde o período colonial escravista quando, segundo Carneiro (2006), a mulata era considerada uma tentadora dos desejos dos homens brancos e era vista como encarnação da lascívia, da sensualidade. Essa visão ainda se mantém na sociedade e no imaginário popular dominante, sendo reforçado pela imprensa.

A categoria das Esportistas e Atletas (EA) reuniu 8,4\% das fotos com mulheres pardas e negras. Das 57 fotos presentes nesse grupo, dez eram da jogadora de futebol Marta. Por último, ficou o conjunto das Políticas e Agentes da Economia (PE), com apenas 3,4\% de presença, dando um total de 23 fotografias. Entretanto, esse último grupo só chegou a essas raras fotos devido à presença de três personagens: a então ministra da Secretaria Especial de Promoção da Igualdade Racial, Matilde Ribeiro, que se encontrava no meio do escândalo do uso dos cartões corporativos; a secretária de Estado dos Estados Unidos, Condoleezza Rice, que veio ao Brasil; e a exministra do Meio Ambiente, Marina Silva. Das 23 fotos encontradas nessa categoria, 19 eram dessas mulheres (82,6\% das ocorrências).

\section{Considerações finais}

O acompanhamento sistemático dos três jornais catarinenses durante cinco meses permitiu concluir que a imprensa do estado pouco contribui para mostrar todas as diferenças culturais e etnias existentes na região. Pelo contrário, atua de forma a reforçar os estereótipos já existentes do habitante eurocêntrico e da inexistência de diversidade étnica. Consciente ou não, deliberada ou inadvertida, essa tendência na imprensa contribui para 
um processo de embranquecimento da população local.

Em todos os jornais analisados, a quantidade de fotografias com mulheres negras e pardas não chegou nem perto de alcançar o percentual delas na população do estado. Os jornais até mostram essas mulheres em todas as editorias, mas longe de algum equilíbrio. As ocorrências ficaram muito concentradas nas seções Variedades/Cultura/Lazer em detrimento de parcela ínfima nas editorias de Destaque, Mundo, Economia e Política, notadamente mais influentes e decisivas nas ações da sociedade. Ao acentuar a presença em alguns setores e relegar outros, a mídia também reforça a distribuição desigual que a realidade nacional ainda alimenta.

A discriminação racial no Brasil não se dá apenas por atitudes que possam ser percebidas, mas principalmente pela ausência, pela exclusão dessas negras nos jornais, pela indiferença que são tratadas e pelo reforço de estereótipos sempre atribuídos a elas de maneira equivocada e preconceituosa.

Os três jornais analisados de Santa Catarina estão reforçando as desigualdades existentes no estado ao tornar mais invisíveis as mulheres negras e pardas. Não se trata de uma criação da imprensa, mas a mídia reflete e fortalece o modo como as parcelas dominantes lidam com as afro-descendentes.

O levantamento que ora apresentamos torna ainda mais agudas as conclusões da pesquisa desenvolvida por Christofoletti e Basso (2007), já que a discriminação ocorre no cruzamento de duas variáveis: etnia e gênero. A mídia funciona como uma vitrine e se as afro-descendentes não aparecem nela, tem-se a impressão de que essas mulheres não existem. A mídia deveria ser uma arena de visibilidade democrática onde todas as camadas da população estivessem representadas. Entretanto, para alcançar essa condição de equilíbrio, visibilidade e representatividade, a imprensa catarinense ainda tem muito a trilhar aAMECOS

\section{NOTAS}

Este artigo é resultante da pesquisa "Mulheres negras nas páginas dos jornais catarinenses", financiada entre 2007-2008 pelo PIBIC-CNPq.

\section{REFERÊNCIAS}

A NOTÍCIA. Brasil, o segundo em desigualdade. Joinville, 2 de junho de 2005.

BUARQUE, Sérgio. Raízes do Brasil. São Paulo: Cia das Letras, 1995.

CARNEIRO, Sueli. Estrelas com luz própria. IN: História Viva Temas Brasileiros, no 3 - Presença Negra. São Paulo: Ediouro e Segmento-Duetto, 2006, pp. 46-51.

Mulheres em movimento. Estudos Avançados. vol.17 n.49, São Paulo, setembro/dezembro, 2003. D i s p o nível em: http:/www.scielo.br scielo.php?script $=$ sci_arttext $\&$ pid $=$ S0103$40142003000300008 \& \operatorname{lng}=\mathrm{es} \& n r m=\mathrm{iso} \& t \operatorname{lng}=\mathrm{es}$. Acesso em 20 de junho de 2008.

CHRISTOFOLETTI, Rogério e BASSO, Marjorie K.J. O preto no branco: democracia midiática no Brasil e presença dos negros nas fotos dos jornais. Estudos em Comunicação, n² 2, pp. 81-96, dezembro de 2007.

IBGE. Pesquisa Nacional por Amostra de Domicílios (PNAD). Brasília, 2003.

IBGE. Pesquisa Nacional por Amostra de Domicílios (PNAD). Brasília, 2004.

IBGE. Pesquisa Nacional por Amostra de Domicílios (PNAD). Brasília, 2006.

IBGE. Sintese dos Indicadores Sociais 2007. Rio de Janeiro, 2007.

MACEDO, Aroldo; FAUSTINO, Oswaldo. A cor do Sucesso. Sete razões de orgulho para a Comunidade afro-brasileira. São Paulo: Gente, 2000.

MINISTÉRIO DA SAÚDE. Perspectiva da Eqüidade no Pacto Nacional pela Redução da Mortalidade Materna e Neonatal: Atenção à Saúde das Mulheres Negras. Brasília, 2005.

PETRY, Sabrina. Até na hora do parto negra é discriminada. Folha Online, 2002. Disponível em: http:// www1.folha.uol.com.br/folha/cotidiano/ ult95u51689.shtml. Acesso em: 20 de junho de 2008

SANTOS, Gislene Aparecida dos. As novelas e seus clichês. IN: História Viva Temas Brasileiros, nº 3 - Presença Negra. São Paulo: Ediouro e Segmento-Duetto, 2006. pp: 52-55.

SODRÉ, Muniz. Claros e escuros. Petrópolis: Vozes, 1999.

TURRA, Cleusa; VENTURI, Gustavo (orgs.). Racismo cordial. SP: Ática, 1995. 